\title{
Radial nerve neurotmesis in closed humeral shaft fracture: unusual case
}

\author{
Prabhu Manickam S.*, Lydia M., Gunalan K., Narayanan V. L., Ezhil Rajan B.
}

Department of Orthopaedics, Saveetha Medical College, Chennai, Tamil Nadu, India

Received: 25 June 2017

Revised: 23 July 2017

Accepted: 24 July 2017

\section{*Correspondence:}

Dr. Prabhu Manickam S.,

E-mail: dr.msprabhu@gmail.com

Copyright: ( $)$ the author(s), publisher and licensee Medip Academy. This is an open-access article distributed under the terms of the Creative Commons Attribution Non-Commercial License, which permits unrestricted non-commercial use, distribution, and reproduction in any medium, provided the original work is properly cited.

\begin{abstract}
Radial nerve neurotmesis constitutes a major problem in the treatment of closed fractures of the mid-shaft of the humerus. A case of radial nerve neurotmesis associated with a closed fracture of mid-shaft of the humerus is reported. Radial nerve neurotmesis was found at the fractured site. Early exploration of the nerve and primary internal fixation of the fracture was done which gave a satisfactory result.
\end{abstract}

Keywords: Closed fracture humerus, Radial nerve neurotmesis, Tinel's sign

\section{INTRODUCTION}

Radial nerve neurotmesis associated with closed fracture of the mid - shaft of the humerus is a rare presentation and constitutes a major problem. There is a rising incidence of humeral shaft fracture in advancing countries where the road condition and driving etiquette do not synchronize. It is estimated that 2,37,000 fractures of the humerus occur in the USA every year. ${ }^{1}$ The radial nerve is injured in approximately $18 \%$ of humeral shaft fractures. ${ }^{2}$ Fractures involving the distal third of the humerus are highly susceptible to radial nerve injury, where as those involving the middle third are not. ${ }^{3}$ Radial neuropraxia is most commonly associated with a mid shaft humeral fracture, whereas neurotmesis of radial nerve is very rare. ${ }^{4}$ Early exploration of the radial nerve claim is technically easier and safer than a delayed procedure. Direct examination of the injured nerve clarifies the diagnosis and the extent of the lesion. Reduction of the fracture helps in reducing further neural damage from mobile bone ends. Early stabilization of the fracture reduces the chance of the nerve being enveloped by scar tissue and callus. ${ }^{5-7}$ we report a rare case of neurotmesis of the radial nerve with closed fracture middle third of shaft of the humerus.

\section{CASE REPORT}

A 28 years old adult male reported to our Emergency with U Plaster cast with history of road traffic accident two days prior to presentation. Initially he was treated elsewhere. He was examined without plaster and found to have the evidence of fracture of left humerus in the middle third with wrist drop, finger drop, thumb drop and numbness of first web space. There was not even a small bruise on his arm. He also had fracture of right clavicle. $\mathrm{X}$-rays showed fracture humerus middle 3rd with small comminution on the medial side (Figure 1A). Nerve conduction study was not performed pre-operatively. He was investigated for anesthesia and surgery. Open reduction and internal fixation with plate osteosynthesis (Figure 1B) of both humerus and clavicle along with primary nerve suturing of the radial nerve (Figure 2B) were done on the $4^{\text {th }}$ day following the injury after freshening the nerve ends and mobilization of distal part of the nerve. Neurotmesis was a per-operative incidental finding and was documented (Figure 2A). He started developing positive Tinel's sign at the back of thumb, dorsum of the radial two and half fingers and hand from the $11^{\text {th }}$ post-operative day. 

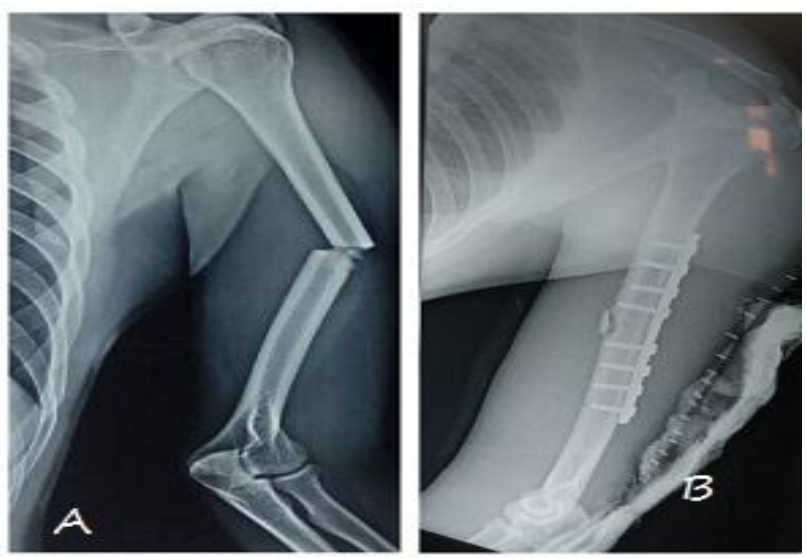

Figure 1: (A) Shows comminuted fracture of left middle third of humerus; (B) Post op picture after fracture reduction and internal fixation.
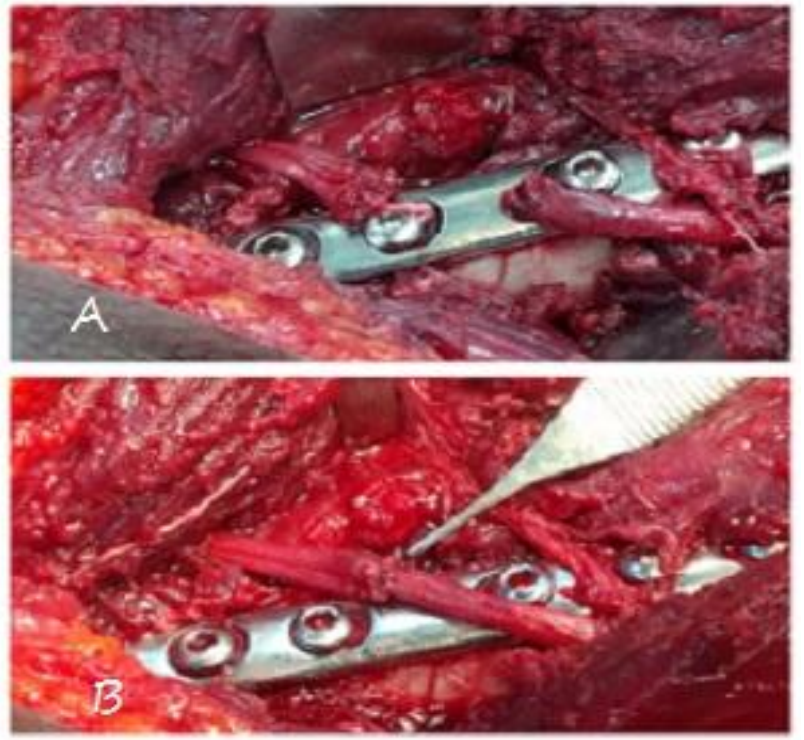

Figure 2: (A) Per-operative picture showing neurotmesis of radial nerve; (B) Per-operative picture after radial nerve repair.

\section{DISCUSSION}

Radial nerve neurotmesis associated with closed comminuted fracture of the middle shaft of the humerus is a very rare presentation. Radial nerve palsy is most commonly seen in transverse $(21.2 \%)$ and spiral fractures $(19.8 \%)$ compared with oblique $(8.4 \%)$ and comminuted $(6.8 \%)$ fractures. $^{4}$ Injury to the radial nerve can cause significant disability and a thorough clinical examination is important following humeral fracture. Inability to extend the wrist and fingers associated with loss of function of the brachioradialis and extensor carpi radialis longus and brevis are an indication of radial nerve injury. Early exploration of the nerve and internal fixation of this fracture is recommended. Several unique anatomical features make the radial nerve particularly vulnerable to injury when humeral shaft occurs. The nerve is intimately related to the humerus in the middle third of the shaft, separated by only a thin layer of triceps muscle. When fracture occurs at the middle shaft of the humerus, the bone ends can easily lacerate, contuse, or entrap the radial nerve. In closed injuries, the radial nerve is intact in the majority of cases and prognosis for complete or near complete recovery is good. ${ }^{2,8-13}$ Early surgical exploration in a closed injury may be indicated when radial nerve neurotmesis is suspected in a comminuted middle shaft of the humeral fracture with associated loss of radial nerve function. ${ }^{11}$ Primary repair has been recommended if it can be performed without significant tension. Tension free repair and freshening up nerve ends before suturing offers better results. Where there is extensive laceration of the nerve, sural nerve grafting offers good functional recovery in about 26 months. ${ }^{14}$

\section{CONCLUSION}

The current case, to our knowledge is first reported case of Radial nerve neurotmesis associated with closed fracture of the mid - shaft of the humerus. In the case discussed here, there was early appreciation of Tinel's sign, probably because of early exploration and primary nerve repair. Hence we believe that early surgical repair and fracture stabilisation is technically easier and safer to achieve nerve recovery and fracture union early.

\section{Funding: No funding sources Conflict of interest: None declared Ethical approval: Not required}

\section{REFERENCES}

1. Green DP. Radial nerve palsy. In: Green DP, Hotchkiss RN, Pederson WC, Wolfe SW, eds. Green's operative hand surgery. Fifth ed. Philadelphia: Elsevier Churchill livingstone; 2005: 1113-29.

2. Mast JW, Spiegel PG, Harvey JP Jr, Harrison C. Fractures of the humeral shaft: a retrospective study of 240 adult fractures. Clin Orthop. 1975;112:25462.

3. Holstein A, Lewis GB (1963). Fractures of the humerus with radial-nerve paralysis. J Bone Joint Surg AM. 1963;45:1382-8.

4. Shao YC, Harwood P, Grotz MRW, Limb D, Giannoudis PV. Radial nerve palsy associated with fracture of the shaft of the humerus: a systemic review. J Bone Joint Surg Br. 2005;87:1647-52.

5. Packer JW, Foster RR, Garcia A, Grantham SA. The humeral fracture with radial nerve palsy: is exploration warranted. Clin Orthop. 1972;88:34-8.

6. Foster RJ, Swiontkowski MF, Bach AW, Sack JT. Radial nerve palsy caused by open humeral shaft fractures. J Hand Surg Am. 1993;18:121-4.

7. Dabezies EJ, Banta CJ 2nd, Murphy CP, d' Ambrosia RD. Plate fixation of the humeral shaft for acute fractures, with and without radial nerve injuries. J Orthop Trauma. 1992;6:10-3. 
8. Amillo S, Barrios RH, Martinez - Peric R, Losada JL. Surgical treatment of radial nerve lesions associated with fractures of the humerus. J Orthop Trauma. 1998:7:211-5.

9. Pallock FH, Drake D, Bovill EG, Day L, Trafton PG. Treatment of radial neuropathy associated with fractures of the humerus. J Bone Joint Surg Am. 1981;63-A:239-43.

10. Samardzic M, Grujicic D, Milinkovic ZB. Radial nerve lesions associated with fracture of the humeral shaft. Injury. 1990;21:220-2.

11. Shah JJ, Bhatti NA. Radial nerve paralysis associated with fractures of the humerus. Clin Orthop. 1983;172:171-6.
12. Shaw JL, Sakellarides H. Radial - nerve paralysis associated with fractures of the humerus:a review of 45 cases. J Bone Joint Surg Am. 1967;49:899-902.

13. Someveld GJ, Patka P, Van Mourik JC, Broere G. Treatment of fractures of the shaft of the humerus accompanied by paralysis of the radial nerve. Injury. 1987;18:404-6.

14. Fisher TR, Mc Geoch CM. Severe injuries of the radial nerve treated by sural nerve grafting. Injury. 1985;16:411-2.

Cite this article as: Prabhu MS, Lydia M, Gunalan K, Narayanan VL, Rajan EB. Radial nerve neurotmesis in closed humeral shaft fracture: unusual case. Int J Res Orthop 2017;3:1078-80. 